\title{
Propofol and magnesium attenuate isoflurane-induced caspase-3 activation via inhibiting mitochondrial permeability transition pore
}

\author{
Yiying Zhang, Yuanlin Dong, Zhipeng Xu and Zhongcong Xie*
}

\begin{abstract}
Background: The inhalation anesthetic isoflurane has been shown to open the mitochondrial permeability transition pore (mPTP) and induce caspase activation and apoptosis, which may lead to learning and memory impairment. Cyclosporine A, a blocker of mPTP opening might attenuate the isoflurane-induced mPTP opening, lessening its ripple effects. Magnesium and anesthetic propofol are also mPTP blockers. We therefore set out to determine whether propofol and magnesium can attenuate the isoflurane-induced caspase activation and mPTP opening.

Methods: We investigated the effects of magnesium sulfate $\left(\mathrm{Mg}^{2+}\right)$, propofol, and isoflurane on the opening of mPTP and caspase activation in $\mathrm{H} 4$ human neuroglioma cells stably transfected to express full-length human amyloid precursor protein (APP) (H4 APP cells) and in six day-old wild-type mice, employing Western blot analysis and flowcytometry.

Results: Here we show that $\mathrm{Mg}^{2+}$ and propofol attenuated the isoflurane-induced caspase-3 activation in H4-APP cells and mouse brain tissue. Moreover, $\mathrm{Mg}^{2+}$ and propofol, the blockers of mPTP opening, mitigated the isoflurane-induced mPTP opening in the H4-APP cells.

Conclusion: These data illustrate that $\mathrm{Mg}^{2+}$ and propofol may ameliorate the isoflurane-induced neurotoxicity by inhibiting its mitochondrial dysfunction. Pending further studies, these findings may suggest the use of $\mathrm{Mg}^{2+}$ and propofol in preventing and treating anesthesia neurotoxicity.
\end{abstract}

\section{Introduction}

Alzheimer's disease (AD) is one of the most common dementia with an incidence of $13 \%$ in people over 65 years of age [1]. There are approximately 8.5 million $\mathrm{AD}$ patients who will need anesthesia and surgery care every year. Anesthesia and surgery have been reported to induce cognitive dysfunction, which $\mathrm{AD}$ patients are susceptible to develop. Therefore, it is important to identify any anesthetic that may promote AD neuropathogenesis and to develop strategies in preventing and treating anesthesia neurotoxicity.

\footnotetext{
* Correspondence: zxie@partners.org

Geriatric Anesthesia Research Unit, Department of Anesthesia, Critical Care and Pain Medicine, Massachusetts General Hospital and Harvard Medical School, 149 13th St. Room 4310, Charlestown, MA 02129-2060, USA
}

Caspase activation and apoptosis have been reported to contribute to $\mathrm{AD}$ neuropathogenesis. ([2-11], reviewed in $[12,13])$ And current studies suggest that caspase activation (without apoptosis) can induce microglia activation, contributing to $\mathrm{AD}$ neuropathogenesis [14]. The commonly used inhalation anesthetic isoflurane has been shown to induce caspase activation and apoptosis, and to increase $\beta$-amyloid protein (A $\beta)$ oligomerization and accumulation in vitro and in vivo [15-23]. Our recent studies have shown that isoflurane can induce mitochondrial dysfunction, e.g., mPTP opening, leading to caspase activation in vitro and in vivo and impairment of learning and memory function in mice [24]. Moreover, cyclosporine A, an inhibitor of MPTP opening [25-33], has been shown to attenuate the isoflurane-induced $\mathrm{mPTP}$ opening, caspase-3 activation, and impairment of learning and memory [24].

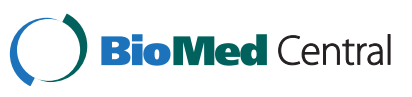


Propofol, the most commonly used intravenous anesthetic, and magnesium sulfate $\left(\mathrm{Mg}^{2+}\right)$ are also blockers of MPTP [34]. In the present studies, we have assessed the effects of propofol and $\mathrm{Mg}^{2+}$ on isoflurane-induced opening of mPTP and caspase- 3 activation.

Both propofol and isoflurane have been shown to be both cytoprotective and cytotoxic, depending on doseand time-differences in various cell cultures and in the developing brains in different animal models [35-38]. Volatile anesthetics or propofol may also provide cardiac or brain protection via opening mitochondrial potassium channels or generation of reactive oxygen species (ROS) in mitochondria $[34,39,40]$.

\section{Methods}

Cells

We employed H4 human neuroglioma cells, stably transfected to express full-length (FL) amyloid precursor protein (APP) (H4-APP cells) in the experiments. The cells were cultured in Dulbecco's Modified Eagle Media (DMEM) containing 9\% heat-inactivated fetal calf serum, 100 units $/ \mathrm{ml}$ penicillin, $100 \mu \mathrm{g} / \mathrm{ml}$ streptomycin, and $2 \mathrm{mM}$ L-glutamine, and were supplemented with $220 \mu \mathrm{g} / \mathrm{ml} \mathrm{G} 418$.

\section{Treatments for H4-APP cells}

Cells were treated with $2 \%$ isoflurane plus $21 \% \mathrm{O}_{2}$ and $5 \%$ $\mathrm{CO}_{2}$ for six hours as described by our previous studies [41] for the purpose of measuring caspase-3 activation. The cultured cells were treated for three hours in the studies to measure MPTP opening as described by our precious studies [24]. Treatment with $2 \%$ isoflurane for three hours may not induce caspase-3 activation and apoptosis (Figure 1). Thus, we assessed whether the treatment with $2 \%$ isoflurane for three hours might induce opening of mPTP without causing caspase- 3 activation in the cells. In the interaction experiments, $50 \mu \mathrm{M}$ magnesium sulfate $\left(\mathrm{Mg}^{2+}\right)$ or $200 \mu \mathrm{M}$ propofol was administrated to the cells one hour before the isoflurane treatment as well as during isoflurane treatment.

\section{Mice anesthesia and harvest of brain tissues}

C57BL/6 J mice (The Jackson Laboratory, Bar Harbor, $\mathrm{ME})$ were used in the experiments as described before $[17,42]$. The animal protocol was approved by Standing Committee on Animals at Massachusetts General Hospital (Boston, MA). The mice were randomized by weight and gender into experimental groups that received $1.4 \%$ isoflurane plus $100 \%$ oxygen for six hours, and control groups that received $100 \%$ oxygen for six hours at identical flow rates in identical anesthetizing chambers. Anesthetic and oxygen concentrations were measured continuously (Datex, Tewksbury, MA), and the temperature of the anesthetizing chamber was controlled to maintain the rectal temperature of the mice at $37 \pm 0.5^{\circ} \mathrm{C}$. In the interaction studies, $\mathrm{Mg}^{2+}(100 \mathrm{mg} / \mathrm{kg})$ or propofol $(50 \mathrm{mg} / \mathrm{kg})$ was administered to the mice via intraperitoneal injection 10 minutes before the isoflurane anesthesia. $200 \mu \mathrm{M}$ propofol has been shown to have neuroprotective effects in an in vitro model of traumatic brain injury[43]; we therefore used this concentration of propofol to determine whether propofol can attenuate the isoflurane-induced mPTP opening. 50 and 100 , but not $25, \mathrm{mg} / \mathrm{kg}$ propofol have been shown to produce neuroprotection effects in ischemic mice models [44]. Thus, we used $50 \mathrm{mg} / \mathrm{kg}$ propofol in the current studies. And we used $100 \mathrm{mg} / \mathrm{kg} \mathrm{Mg}^{2+}$ on mice because $\mathrm{Mg}^{2+}$ has been shown to have a neuroprotective effect on cerebral ischemia [45]. And based on our preliminary results, we used $50 \mu \mathrm{M} \mathrm{Mg}^{2+}$ in the in vitro the studies. Whole brain tissues of mice were harvested at end of the anesthesia.

\section{Brain tissue lysis and protein amount quantification}

The harvested brain tissues were homogenized on ice using an immunoprecipitation buffer $(10 \mathrm{mM}$ Tris- $\mathrm{HCl}, \mathrm{pH} 7.4$, $150 \mathrm{mM} \mathrm{NaCl}, 2 \mathrm{mM}$ EDTA, 0.5\% Nonidet P-40) plus protease inhibitors $(1 \mu \mathrm{g} / \mathrm{ml}$ aprotinin, $1 \mu \mathrm{g} / \mathrm{ml}$ leupeptin, $1 \mu \mathrm{g} / \mathrm{ml}$ pepstatin A). The lysates were collected, centrifuged at 13,000 rpm for $15 \mathrm{~min}$, and quantified for total proteins by a bicinchoninic acid protein assay kit (Pierce, Iselin, NJ).

\section{Western blots analysis}

The harvested H4-APP cells and brain tissues were subjected to Western blot analyses as described by Xie et al. $[17,18,20]$ and Zhang et al. [46,47]. A caspase-3 antibody (1:1,000 dilution; Cell Signaling Technology, Inc., Danvers, MA) was used to recognize FL-caspase-3 (35 - $40 \mathrm{kDa})$ and caspase-3 fragment $(17-20 \mathrm{kDa})$ resulting from cleavage at asparate position 175 . Antibody anti- $\beta$-Actin (1:10,000, Sigma, St. Louis, MO) was used to detect $\beta$-Actin (42 kDa). Each band in the Western blot represented an independent experiment. The results were averaged from three to 8 independent experiments. Briefly, the intensity of the signals was analyzed using the National Institute of Health image program (National Institute of Health Image 1.62, Bethesda, MD). The caspase- 3 normalization was performed by determining the ratio of caspase- 3 fragment to FL caspase- 3 . Then, the changes in levels of caspase- 3 in treated cells or mice were presented as percentages of the corresponding levels in control cells or mice.

\section{Flow cytometric analysis of mPTP opening}

H4-APP cells were treated with $2 \%$ isoflurane for three hours. For the interaction studies, $50 \mu \mathrm{M} \mathrm{Mg}^{2+}$ or 200 $\mu \mathrm{M}$ propofol was administrated to cells one hour before the isoflurane treatment. The opening of MPTP was determined by flowcytometry, using the MitoProbe ${ }^{\mathrm{TM}}$ 


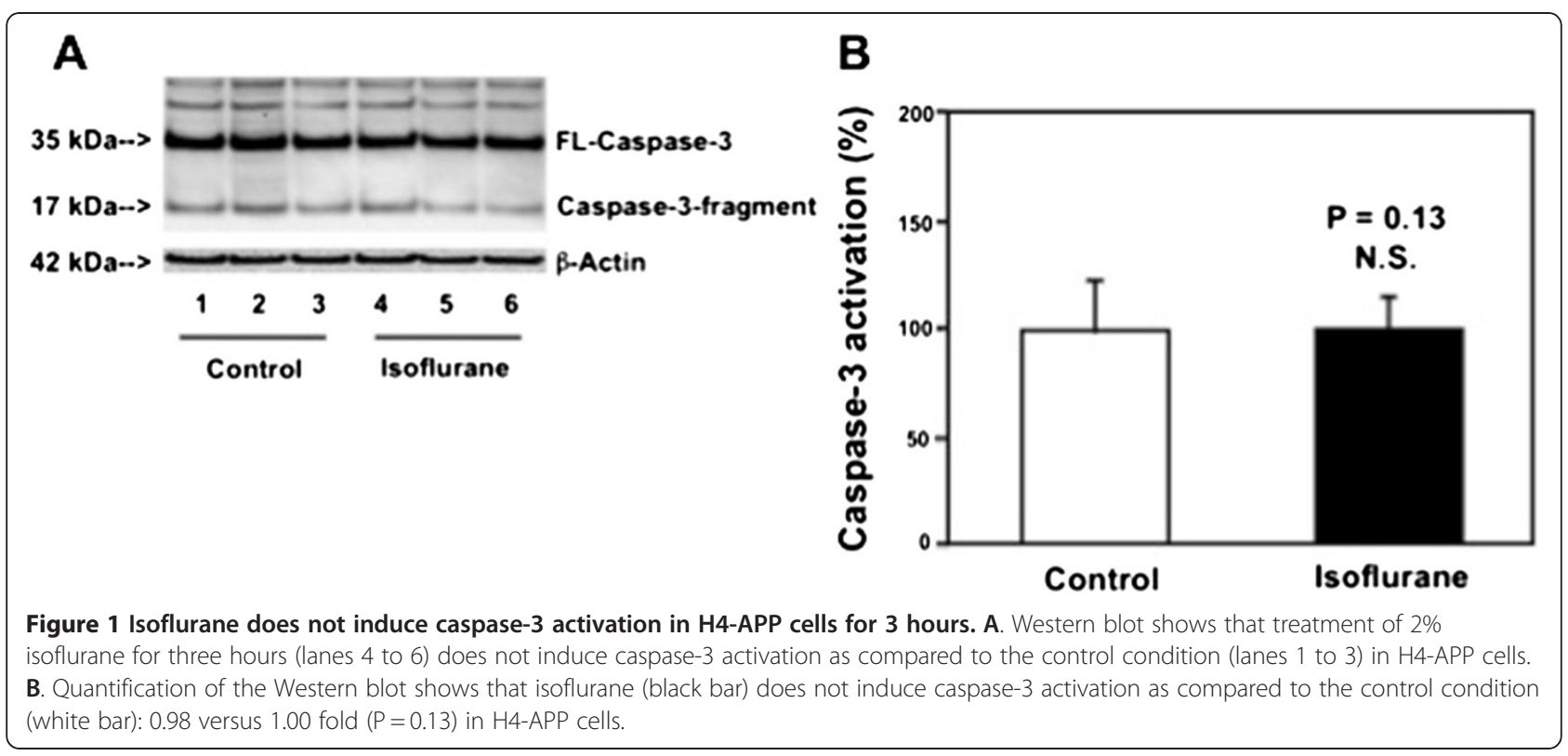

Transition Pore Assay Kit (Invitrogen, Carlsbad, CA). In normal conditions, the non-fluorescent acetoxymethyl ester (AM) of calcein dye (calcein AM) and cobalt can enter the cell. The acetoxymethyl ester (AM) groups are cleaved from calcein via non-specific esterase, and calcein can then show fluorescence signals in both the cytosol and mitochondria. Cobalt can quench the cytosolic calcein signal. However, cobalt cannot enter healthy mitochondria freely, and therefore cannot quench the mitochondrial calcein signal. When opening of mPTP occurs, cobalt enters through the pore and subsequently quenches the mitochondrial calcein signal. Flowcytometry was used to detect the amount of cells that exhibit quenched calcein signals inside the mitochondria. The location of the curves indicates the amount of such cells, which suggests the opening of mPTP. Ionomycin was used as a positive control for the opening of mPTP in the experiments. Dead cells and debris were excluded from analysis by gates set on forward and side angle light scatter.

\section{Statistics}

Given the presence of background caspase 3 activation in cells and brain tissues of mice, we did not use absolute values to describe these changes. Instead, these changes were presented as percentages of those from the control group. For example, one hundred percent of caspase3 activation refers to the control level for the purpose of comparison to experimental conditions. Data were expressed as mean \pm S.D. . The number of samples varied from three to 8 , and the samples were normally distributed. We used a two-tailed $t$-test to compare the difference between the control condition and isoflurane treatment, and the difference between propofol, $\mathrm{Mg}^{2+}$ and their controls.
P-values less than 0.05 (* or \#) and 0.01 (** or \#\#) were considered statistically significant.

\section{Results}

$\mathrm{Mg}^{2+}$ inhibited the isoflurane-induced caspase-3 activation in H4-APP cells and in brain tissues of mice The H4-APP cells were treated with $50 \mu \mathrm{M} \mathrm{Mg}^{2+}$ or saline for 10 minutes followed by $2 \%$ isoflurane or control condition for six hours. The cells were harvested at the end of the experiment and were subjected to Western blot analysis. Caspase-3 immunoblotting revealed that the isoflurane treatment induced caspase-3 activation (Figure 2A) as evidenced by increased ratios of cleaved (activated) caspase-3 fragment (17 kDa) to full-length (FL) (35-40 kDa) caspase-3. Treatment with $50 \mu \mathrm{M} \mathrm{Mg}^{2+}$ alone did not induce caspase- 3 activation, but the $\mathrm{Mg}^{2+}$ treatment attenuated the isoflurane-induced caspase- 3 activation (Figure 2A). Quantification of the Western blots (Figure 2B), based on the ratio of caspase-3 fragment to FL caspase-3, revealed that isoflurane (black bar) led to caspase- 3 activation as compared to the control condition (white bar): 1.54 versus 1.00 fold (** $\mathrm{P}=0.001$ ). The $\mathrm{Mg}^{2+}$ treatment (net bar) attenuated the isoflurane-induced caspase-3 activation: 1.23 fold versus 1.54 fold (\# $\mathrm{P}=0.03$ ). These findings suggest that $\mathrm{Mg}^{2+}$ may mitigate the isoflurane-induced caspase-3 activation in H4-APP cells.

Next, we performed the in vivo relevance studies by assessing the effects of isoflurane and $\mathrm{Mg}^{2+}$ on caspase- 3 activation in the brain tissues of six-day old WT mice. As can be seen in Figure 2C, $\mathrm{Mg}^{2+}$ (lane 4) attenuated the isoflurane-induced caspase-3 activation (lane 3) in the brain tissues of the mice. The $\mathrm{Mg}^{2+}$ treatment alone (lane 2) did not induce caspase-3 activation as compared 
to the saline group (lane 1) in the brain tissues of the mice. Quantification of the Western blot further illustrated that the isoflurane (black bar) led to caspase-3 activation as compared to the control condition (white bar): 1.52 versus 1.00 fold (* $\mathrm{P}=0.02$ ). $\mathrm{Mg}^{2+}$ treatment (net bar) attenuated the isoflurane-induced caspase-3 activation (black bar): 1.38 versus 1.52 fold (\# $\mathrm{P}=0.03$ ), (Figure 2D). These results from the in vivo studies further suggest that $\mathrm{Mg}^{2+}$ may attenuate the isoflurane-induced caspase- 3 activation.
Propofol inhibited isoflurane-induced caspase- 3 activation in brain tissues of mice

Our previous studies have illustrated that propofol can attenuate the isoflurane-induced caspase- 3 activation in H4-APP cells. [48]. In the current experiments, we performed the in vivo relevance studies by assessing the effects of isoflurane and propofol on caspase-3 activation in the brain tissues of WT six-day old mice. As can be seen in Figure 3A, propofol (lane 10-11) attenuated the isoflurane-induced caspase- 3 activation (lane 7-9) in the

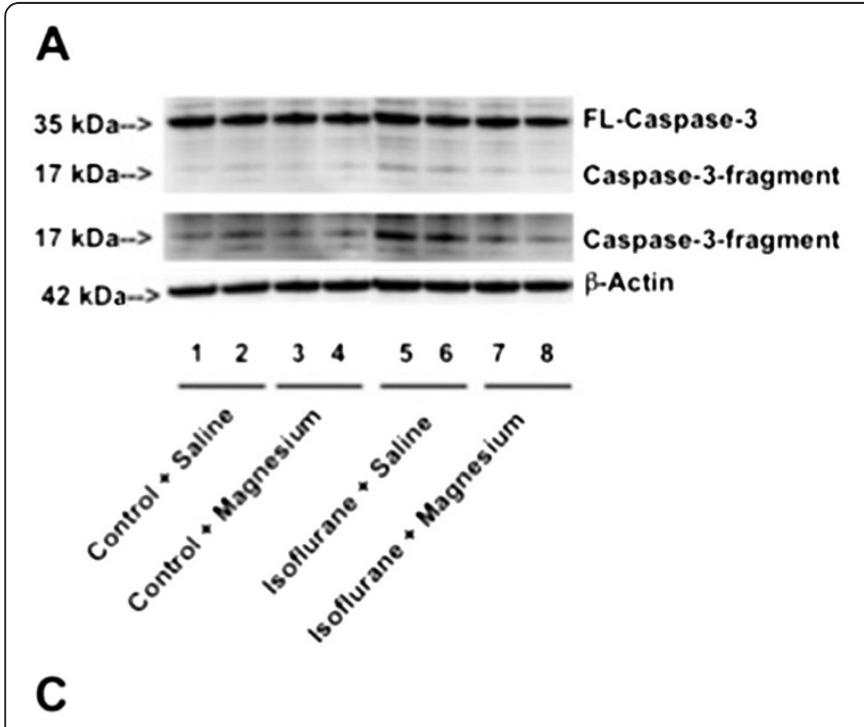

B
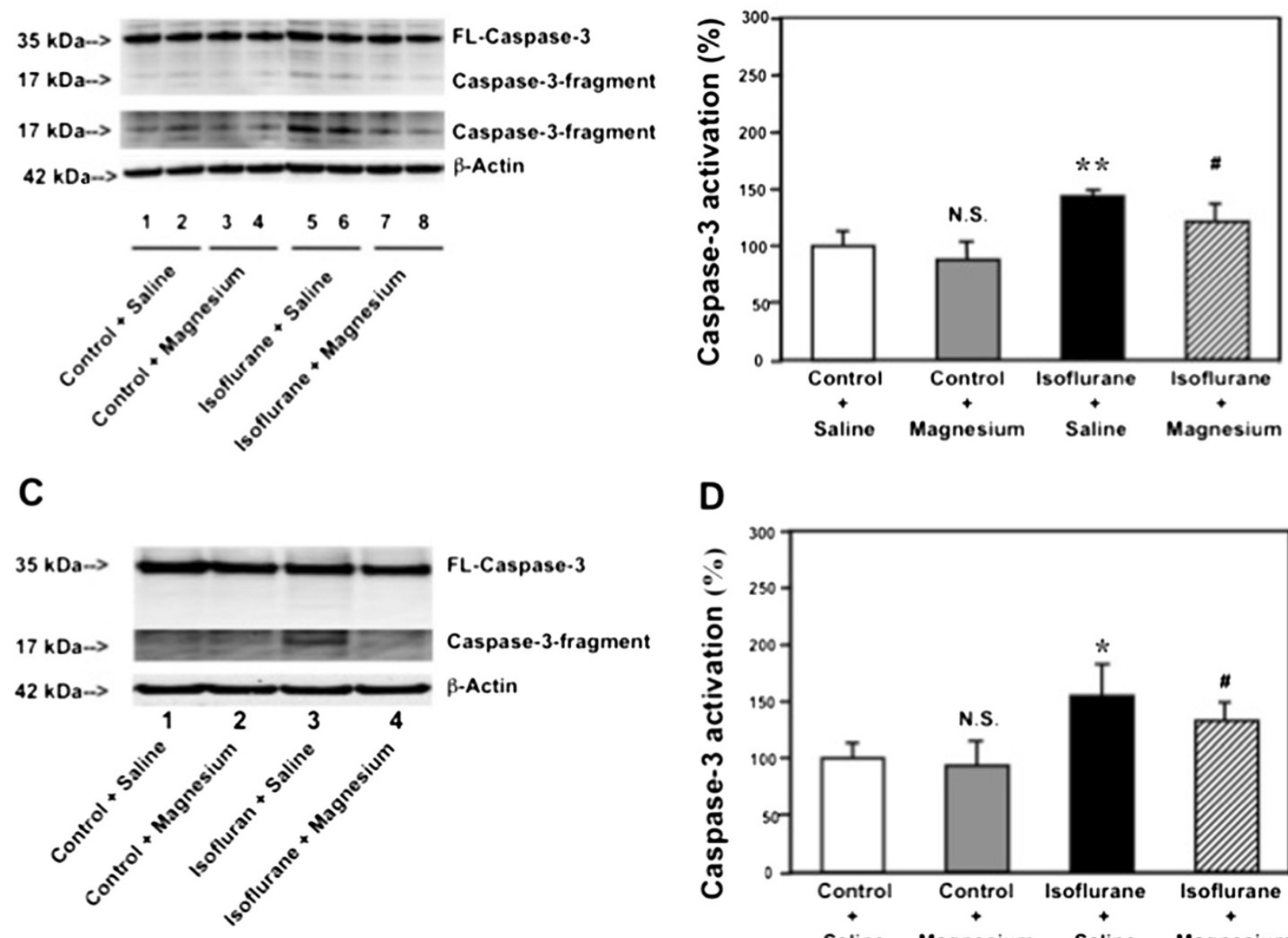

D

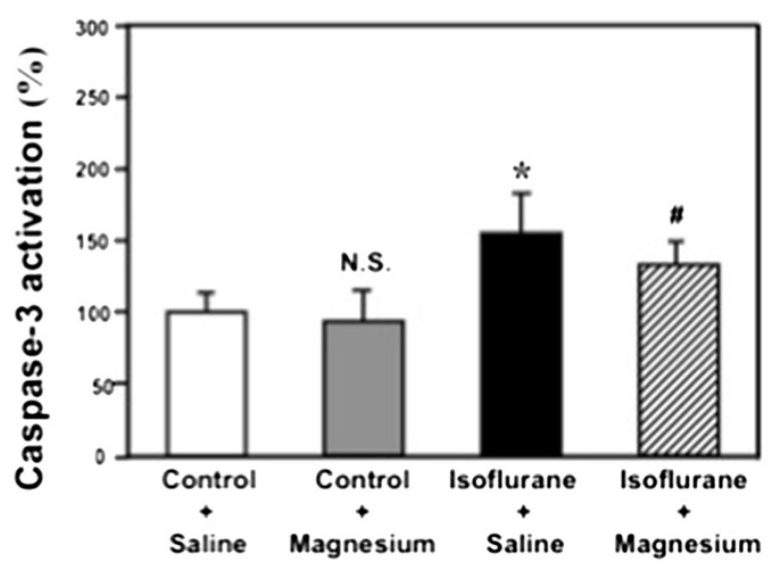

Figure $\mathbf{2} \mathbf{M g}^{2+}$ attenuates isoflurane-induced caspase-3 activation in H4-APP cells and brain tissues of mice. A. Western blot shows that treatment of $2 \%$ isoflurane for six hours (lanes 5 and 6) induces caspase-3 activation as compared to the control condition (lanes 1 and 2) in H4APP cells. $\mathrm{Mg}^{2+}$ treatment alone (lanes 3 and 4) does not induce caspase-3 activation as compared to the control condition (lanes 1 and 2), but $\mathrm{Mg}^{2+}$ treatment attenuates isoflurane-induced caspase-3 activation (lanes 7 and 8) as compared to isoflurane treatment (lanes 5 and 6) in H4-APP cells. B. Quantification of the Western blot shows that isoflurane (black bar) induces caspase-3 activation as compared to the control condition (white bar): 1.54 versus 1.00 fold (** $\mathrm{P}=0.001$ ) in $\mathrm{H} 4-\mathrm{APP}$ cells. $\mathrm{Mg}^{2+}$ treatment (net bar) attenuates isoflurane-induced caspase- 3 activation as compared to isoflurane treatment (black bar): 1.23 fold versus 1.54 fold (\# P=0.03) in H4-APP cells. C. Western blots shows that treatment of $1.4 \%$ isoflurane for six hours (lane 3 ) induces caspase-3 activation as compared to the control condition (lane 1) in mouse brain tissues. $\mathrm{Mg}^{2+}$ treatment alone (lane 2) does not induce caspase-3 activation as compared to the control condition (lane 1), but $\mathrm{Mg}^{2+}$ treatment attenuates isoflurane-induced caspase-3 activation (lane 4) as compared to isoflurane treatment (lane 3) in mouse brain tissues. D. Quantification of the Western blot shows that isoflurane (black bar) induces caspase-3 activation as compared to the control condition (white bar): 1.52 versus 1.00 fold ( ${ }^{*} \mathrm{P}=0.02$ ) in mouse brain tissues. $\mathrm{Mg}^{2+}$ treatment (net bar) attenuates isoflurane-induced caspase-3 activation as compared to isoflurane treatment (black bar): 1.38 versus 1.52 fold (\# $P=0.03$ ) in mouse brain tissues. 


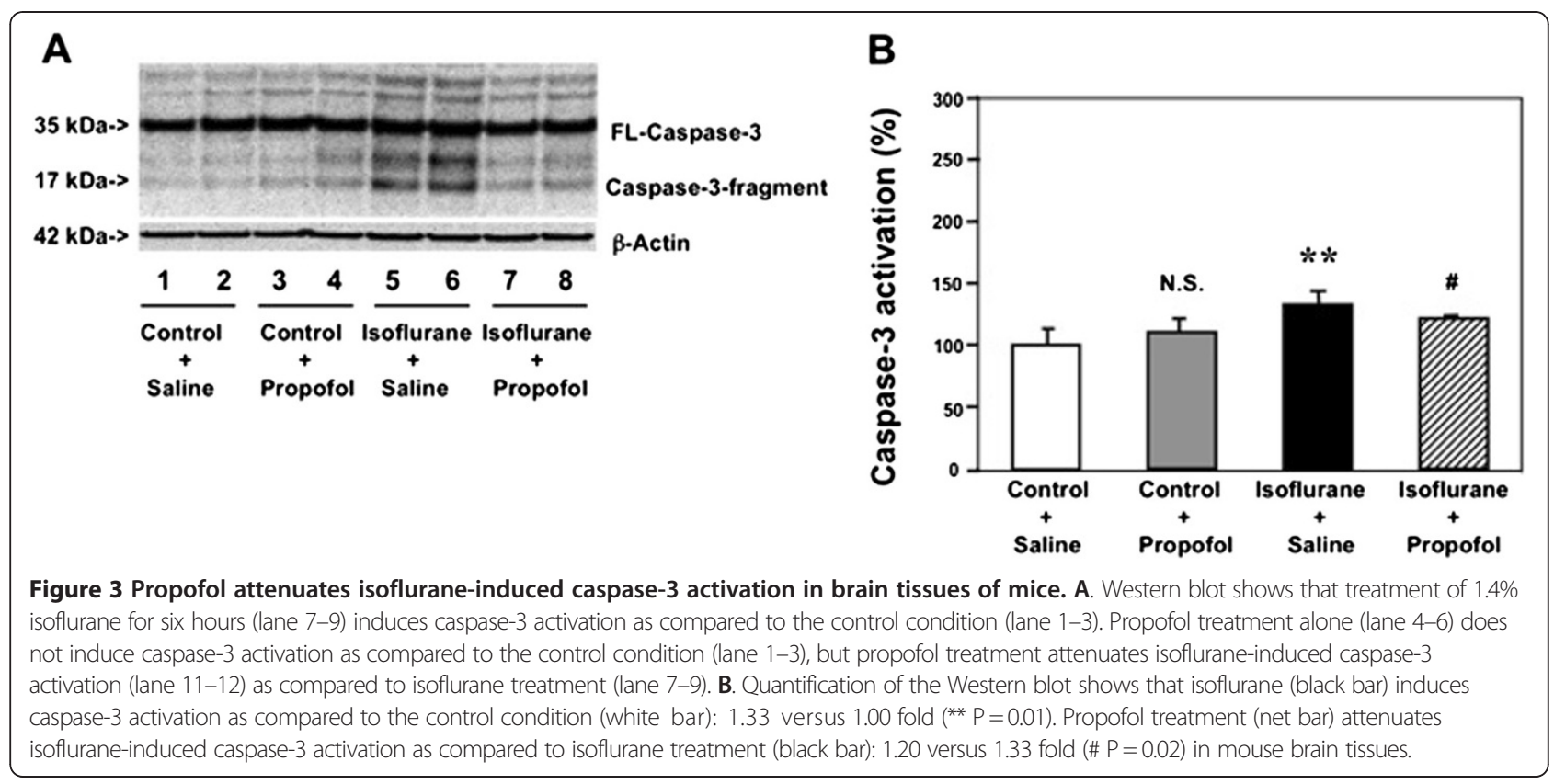

brain tissues of the mice. The propofol treatment alone (lane 4-6) did not induce caspase-3 activation compared with the saline group (lane 1-3) in the brain tissues of the mice. Quantification of the Western blot further illustrated that the isoflurane anesthesia (black bar) led to caspase- 3 activation as compared to the control condition (white bar): 1.33 versus 1.00 fold $\left.{ }^{* * *} \mathrm{P}=0.01\right)$. Propofol treatment (net bar) attenuated the isofluraneinduced caspase- 3 activation in the mice (black bar): 1.20 versus 1.33 fold (\# $\mathrm{P}=0.02$ ), (Figure $3 \mathrm{~B}$ ). These results from the in vivo studies further suggest that propofol may attenuate the isoflurane-induced caspase-3 activation.

\section{$\mathrm{Mg}^{2+}$ and propofol inhibit isoflurane-induced opening of MPTP}

Given that $\mathrm{Mg}^{2+}$ and propofol can attenuate the isofluraneinduced caspase- 3 activation, and the isoflurane-induced caspase- 3 activation may result from the isoflurane-induced opening of mPTP, next, we asked whether $\mathrm{Mg}^{2+}$ and propofol, the blockers of mPTP opening, can attenuate the isoflurane-induced mPTP opening.

Flow cytometric analysis of calceinAM and cobalt showed that the treatment with $50 \mu \mathrm{M} \mathrm{Mg}^{2+}$ (Figure 4, peak 3) led to reductions in the isoflurane-induced mPTP opening (Figure 4, peak 2), as evidenced by the right-shift of the curve, whereas the $\mathrm{Mg}^{2+}$ treatment alone did not affect the opening of mPTP in H4-APP cells (data not shown). Next, we found that the treatment with $50 \mu \mathrm{M}$ propofol (Figure 5, peak 3 ) led to reductions in the isoflurane-induced mPTP opening (Figure 5, peak 2), whereas the propofol treatment alone did not affect the opening of mPTP in H4-APP cells (data not shown). Taken together, these findings suggested that $\mathrm{Mg}^{2+}$ and propofol may mitigate the isoflurane-induced caspase- 3 activation by inhibiting the isoflurane-induced opening of $\mathrm{mPTP}$.

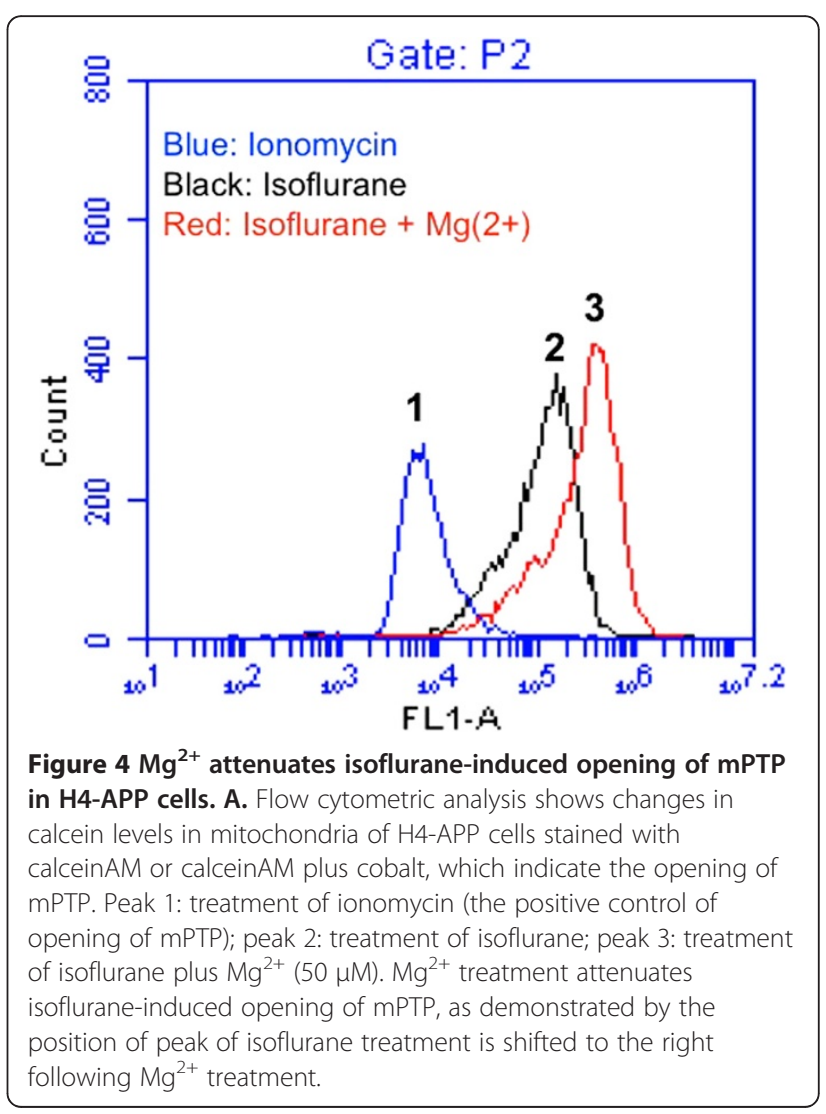




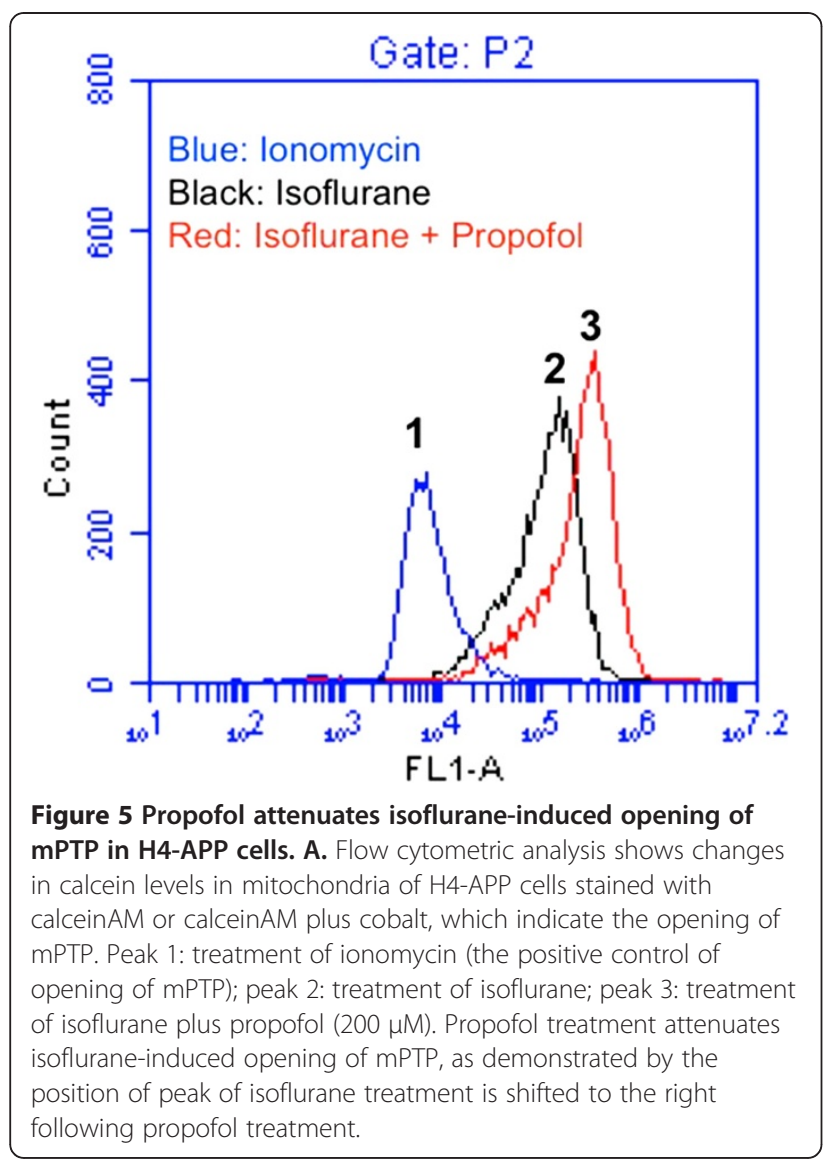

\section{Discussion}

Previous studies have shown that the common inhalation anesthetic isoflurane may induce neurotoxicity in vitro [18] and in vivo [17], which may lead to learning and memory impairment in mice $[24,49,50]$ and cognitive dysfunction in humans [24]. In our search for the strategy to prevent and treat isoflurane neurotoxicity, we were able to show that mPTP inhibitor CsA could attenuate the isofluraneinduced mitochondrial dysfunction (e.g., inhibition of $\mathrm{mPTP}$ ) and caspase- 3 activation. However, CsA is not routinely used in patients due to its nephrotoxicity, hepatotoxicity and cardiotoxicity side effect [51]. Therefore, it is important to assess whether other mPTP inhibitors can also attenuate the isoflurane-induced neurotoxicity.

We have found that both propofol and $\mathrm{Mg}^{2+}$, two chemicals with no significant side effects, can attenuate the isoflurane-induced caspase- 3 activation in vitro and in the brain tissues of mice (Figures 2 and 3). These data suggest that propofol and $\mathrm{Mg}^{2+}$ may attenuate the isoflurane-induced neurotoxicity.

For the mechanistic studies, we have shown that both $\mathrm{Mg}^{2+}$ (Figure 4) and propofol (Figure 5) can inhibit the isoflurane-induced mPTP opening. Our previous studies have revealed that isoflurane may induce caspase activation, apoptosis, and learning and memory impairment by inducing mitochondrial dysfunction (e.g., mPTP opening) $[24,46]$. Collectively, These findings suggest that propofol and magnesium may mitigate the isoflurane-induced caspase- 3 activation by inhibiting the isoflurane-induced $\mathrm{MPTP}$ opening, pending on further studies (Figure 6).

The studies have a few limitations. First, we did not assess whether $\mathrm{Mg}^{2+}$ and propofol can ameliorate the isofluraneinduced learning and memory impairment. However, the findings from the current studies showed that $\mathrm{Mg}^{2+}$ and propofol inhibit the isoflurane-induced mitochondrial dysfunction and neurotoxicity would establish a system for future studies in animals and in humans. Second, we only measured caspase- 3 activation in current studies. This is because our previous studies have already shown that isoflurane can induce caspase- 3 activation, apoptosis, $A \beta$ accumulation, and neuroinflammation $[17,18,20,52]$. In addition, a recent study by Burguillos et al. [14] has shown that caspase activation alone without apoptosis may still be able to contribute to AD neuropathogenesis. Meanwhile, $\mathrm{Mg}^{2+}$ is a well-known NMDA receptor antagonist [53]. Isoflurane has been shown to induce neurotoxicity by increased activation of the NMDA receptor [41]. Therefore, it cannot be excluded that $\mathrm{Mg}^{2+}$ may inhibit the isofluraneinduced neurotoxicity by inhibiting its effects on the NMDA receptor. Isoflurane may induce neurotoxicity via ROS generation $[46,54]$ and potassium channel activity [55]. Propofol may also affect ROS generation and potassium channel activity in mitochondria [56,57]. Thus, it is also possible that propofol may mitigate the isofluraneinduced caspase activation through ROS and potassium channel activity.

In conclusion, we have found that $\mathrm{Mg}^{2+}$ and propofol can attenuate commonly used inhalation anesthetic isoflurane-induce caspase-3 activation in vitro and

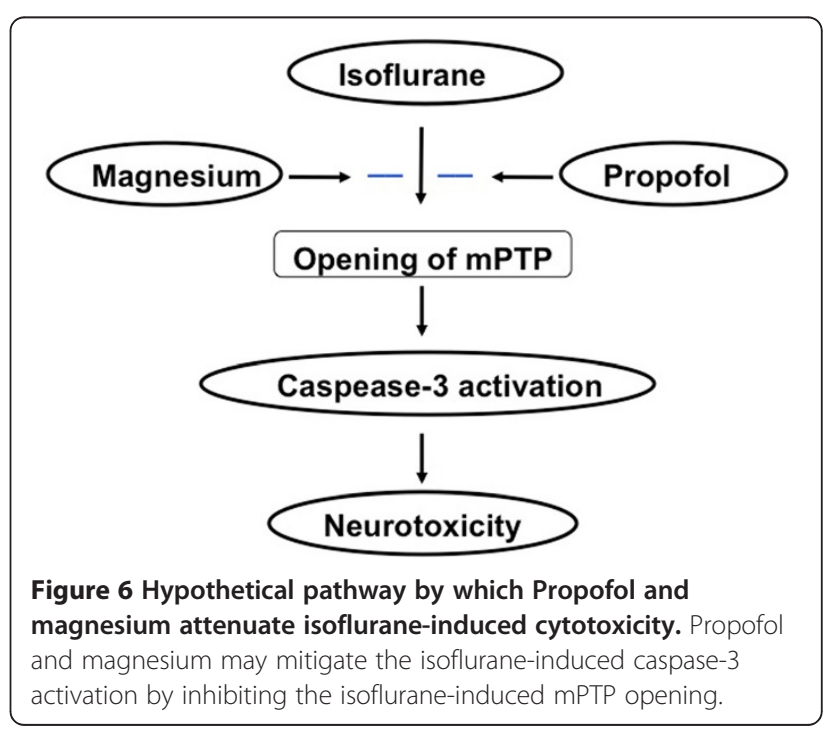


in vivo. Furthermore, we have found that $\mathrm{Mg}^{2+}$ and propofol, the blockers of mPTP opening, can attenuate isoflurane-induced opening of MPTP.

Our current findings should lead to additional studies to determine the potential effects of anesthetics on $\mathrm{AD}$ neuropathogenesis, the underlying mechanisms, and the strategy for prevention and treatment. Ultimately, these combined efforts of anesthesia and neurology may develop guidelines regarding how to provide safer anesthesia care for $\mathrm{AD}$ patients (e.g., to avoid worsening of AD neuropathogenesis and decline of cognitive function by anesthesia and surgery), like the one developed by combined efforts of anesthesia and cardiology on safer anesthesia care for coronary artery disease patients.

\section{Abbreviations}

AD: Alzheimer's disease; APP: Amyloid $\beta$ precursor protein; $A \beta$ : $\beta$-amyloid protein; SD: Standard deviation; SEM: Standard error of mean; CsA: Cyclosporine A; mPTP: Mitochondrial permeability transition pores; calcein AM: Calcein acetoxymethyl ester.

\section{Competing interests}

The authors have no conflicts of interest for the study.

\section{Authors' contributions}

YZ Study concept and design, Acquisition of data, Analysis and interpretation of data, Drafting of the manuscript, Critical revision of the manuscript for important intellectual content. YD and ZX Analysis and interpretation of data. ZX Obtained funding, Study concept and design, Analysis and interpretation of data, Drafting of the manuscript, Critical revision of the manuscript for important intellectual content, Study supervision. All authors read and have approved the manuscript.

\section{Acknowledgement}

This research was supported by R21AG029856, R21AG038994 and R01 GM088801 (National Institutes of Health), USA and Cure Alzheimer's Fund, USA (to Z.X.). The cost of anesthetic isoflurane was generously provided by the Department of Anesthesia, Critical Care and Pain Medicine, Massachusetts General Hospital and Harvard Medical School, Boston, MA, USA. The Flow cytometric analysis was performed in the Cell Biology Core of Harvard Clinic Nutrition Research Center (P30 DK040561). The authors thank Dr. Hai Ning Shi from Mucosal Immunology Laboratory, Massachusetts General Hospital and Harvard Medical School, Charlestown, MA for the technical support in the studies of flow cytometric analysis.

Received: 6 June 2012 Accepted: 3 August 2012

Published: 17 August 2012

\section{References}

1. Thies W, Bleiler L: 2011 Alzheimer's disease facts and figures. Alzheimers Dement 2011, 7(2):208-244

2. Lunkes A, Trottier Y, Mandel JL: Pathological mechanisms in Huntington's disease and other polyglutamine expansion diseases. Essays Biochem 1998, 33:149-163.

3. Namura S, et al: Activation and cleavage of caspase- 3 in apoptosis induced by experimental cerebral ischemia. J Neurosci 1998, 18(10):3659-3668

4. Holtzman DM, Deshmukh M: Caspases: a treatment target for neurodegenerative disease? Nat Med 1997, 3(9):954-955.

5. Kim TW, et al: Alternative cleavage of Alzheimer-associated presenilins during apoptosis by a caspase-3 family protease. Science 1997, 277(5324):373-376

6. Loetscher $\mathrm{H}$, et al: Presenilins are processed by caspase-type proteases. J Biol Chem 1997, 272(33):20655-20659.

7. Barnes NY, et al: Increased production of amyloid precursor protein provides a substrate for caspase-3 in dying motoneurons. J Neurosci 1998, 18(15):5869-5880.
8. Kovacs DM, et al: Staurosporine-induced activation of caspase- 3 is potentiated by presenilin 1 familial Alzheimer's disease mutations in human neuroglioma cells. J Neurochem 1999, 73(6):2278-2285.

9. Su JH, et al: Immunohistochemical evidence for apoptosis in Alzheimer's disease. Neuroreport 1994, 5(18):2529-2533.

10. Su JH, Deng G, Cotman CW: Bax protein expression is increased in Alzheimer's brain: correlations with DNA damage, $\mathrm{BCl}-2$ expression, and brain pathology. J Neuropathol Exp Neurol 1997, 56(1):86-93.

11. Tesco G, et al: Depletion of GGA3 stabilizes BACE and enhances betasecretase activity. Neuron 2007, 54(5):721-737.

12. Mattson MP: Contributions of mitochondrial alterations, resulting from bad genes and a hostile environment, to the pathogenesis of Alzheimer's disease. Int Rev Neurobiol 2002, 53:387-409.

13. Raina AK, et al: Apoptotic promoters and inhibitors in Alzheimer's disease: Who wins out? Prog Neuropsychopharmacol Biol Psychiatry 2003, 27(2):251-254

14. Burguillos MA, et al: Caspase signalling controls microglia activation and neurotoxicity. Nature 2011, 472(7343):319-324.

15. Eckenhoff RG, et al: Inhaled anesthetic enhancement of amyloid-beta oligomerization and cytotoxicity. Anesthesiology 2004, 101(3):703-709.

16. Brambrink $\mathrm{AM}$, et al: Isoflurane-induced neuroapoptosis in the neonatal rhesus macaque brain. Anesthesiology 2010, 112(4):834-841.

17. Xie Z, et al: The common inhalation anesthetic isoflurane induces caspase activation and increases amyloid beta-protein level in vivo. Ann Neurol 2008, 64(6):618-627.

18. Xie $Z$, et al: The common inhalation anesthetic isoflurane induces apoptosis and increases amyloid beta protein levels. Anesthesiology 2006, 104(5):988-994.

19. Xie Z, et al: Isoflurane-induced apoptosis: a potential pathogenic link between delirium and dementia. The journals of gerontology. Series A. Biological sciences and medical sciences 2006, 61(12):1300-1306.

20. Xie Z, et al: The inhalation anesthetic isoflurane induces a vicious cycle of apoptosis and amyloid beta-protein accumulation. J Neurosci 2007, 27(6): 1247-1254.

21. Wei $\mathrm{H}$, et al: Isoflurane and sevoflurane affect cell survival and BCL-2/BAX ratio differently. Brain Res 2005, 1037(1-2):139-147.

22. Wei $\mathrm{H}$, et al: The common inhalational anesthetic isoflurane induces apoptosis via activation of inositol 1,4,5-trisphosphate receptors. Anesthesiology 2008, 108(2):251-260.

23. Loop T, Priebe HJ: Costs of anaesthesia. Eur J Anaesthesiol 2005, 22(2):162. author reply 162-3.

24. Zhang $B$, et al: The effects of isoflurane and desflurane on cognitive function in humans. Anesth Analg 2012, 114(2):410-415.

25. Fournier N, Ducet $\mathrm{G}$, Crevat $A$ : Action of cyclosporine on mitochondrial calcium fluxes. J Bioenerg Biomembr 1987, 19(3):297-303.

26. Bernardi P: The permeability transition pore. Control points of a cyclosporin A-sensitive mitochondrial channel involved in cell death. Biochim Biophys Acta 1996, 1275(1-2):5-9.

27. Bernardi $\mathrm{P}$, Petronilli V: The permeability transition pore as a mitochondrial calcium release channel: a critical appraisal. J Bioenerg Biomembr 1996, 28(2):131-138.

28. Hansson MJ, et al: Brain-derived respiring mitochondria exhibit homogeneous, complete and cyclosporin-sensitive permeability transition. J Neurochem 2004, 89(3):715-729.

29. He L, Lemasters JJ: Dephosphorylation of the Rieske iron-sulfur protein after induction of the mitochondrial permeability transition. Biochem Biophys Res Commun 2005, 334(3):829-837.

30. Nicolli $A$, et al: Interactions of cyclophilin with the mitochondrial inner membrane and regulation of the permeability transition pore, and cyclosporin A-sensitive channel. J Biol Chem 1996, 271(4):2185-2192.

31. Norman $\mathrm{KG}$, et al: Cyclosporine A suppresses keratinocyte cell death through MPTP inhibition in a model for skin cancer in organ transplant recipients. Mitochondrion 2010, 10(2):94-101.

32. Alessandri B, et al: Cyclosporin A improves brain tissue oxygen consumption and learning/memory performance after lateral fluid percussion injury in rats. J Neurotrauma 2002, 19(7):829-841.

33. Osman MM, et al: Cyclosporine-A as a neuroprotective agent against stroke: its translation from laboratory research to clinical application. Neuropeptides 2011, 45(6):359-368.

34. Halestrap AP, Clarke SJ, Javadov SA: Mitochondrial permeability transition pore opening during myocardial reperfusion-a target for cardioprotection. Cardiovasc Res 2004, 61(3):372-385. 
35. Wei $H$, Liang $G$, Yang $H$ : Isoflurane preconditioning inhibited isofluraneinduced neurotoxicity. Neurosci Lett 2007, 425(1):59-62.

36. Ljubkovic $M$, et al: Isoflurane preconditioning uncouples mitochondria and protects against hypoxia-reoxygenation. Am J Physiol Cell Physiol 2007, 292(5):C1583-C1590.

37. Pan $C$, et al: The potential dual effects of anesthetic isoflurane on hypoxia-induced caspase- 3 activation and increases in beta-site amyloid precursor protein-cleaving enzyme levels. Anesth Analg 2011, 113(1): $145-152$.

38. Xu Z, et al: The potential dual effects of anesthetic isoflurane on Abetainduced apoptosis. Curr Alzheimer Res 2011, 8(7):741-752.

39. Zaugg $M$, et al: Differential effects of anesthetics on mitochondrial K(ATP) channel activity and cardiomyocyte protection. Anesthesiology 2002, 97(1):15-23.

40. Jiang MT, et al: Isoflurane activates human cardiac mitochondrial adenosine triphosphate-sensitive $\mathrm{K}+$ channels reconstituted in lipid bilayers. Anesth Analg 2007, 105(4):926-932. table of contents.

41. Zhang G, et al: Isoflurane-induced caspase-3 activation is dependent on cytosolic calcium and can be attenuated by memantine. J Neurosci 2008 , 28(17):4551-4560

42. Lu Y, et al: Anesthetic sevoflurane causes neurotoxicity differently in neonatal naive and Alzheimer disease transgenic mice. Anesthesiology 2010, 112(6):1404-1416.

43. Rossaint J, et al: Propofol: neuroprotection in an in vitro model of traumatic brain injury. Crit Care 2009, 13(2):R61.

44. Shu $L$, et al: Inhibition of neuron-specific CREB dephosphorylation is involved in propofol and ketamine-induced neuroprotection against cerebral ischemic injuries of mice. Neurochem Res 2012, 37(1):49-58.

45. Marinov MB, et al: Neuroprotective effects of preischemia intraarterial magnesium sulfate in reversible focal cerebral ischemia. J Neurosurg 1996, 85(1):117-124.

46. Zhang $Y$, et al: The mitochondrial pathway of anesthetic isofluraneinduced apoptosis. J Biol Chem 2010, 285(6):4025-4037.

47. Zhang J, et al: 2-Deoxy-D-glucose attenuates isoflurane-induced cytotoxicity in an in vitro cell culture model of $\mathrm{H} 4$ human neuroglioma cells. Anesth Analg 2011, 113(6):1468-1475.

48. Zhang $Y$, et al: Anesthetic propofol attenuates the isoflurane-induced caspase-3 activation and Abeta oligomerization. PLoS One 2011, 6(11): e27019.

49. Culley DJ, et al: Long-term impairment of acquisition of a spatial memory task following isoflurane-nitrous oxide anesthesia in rats. Anesthesiology 2004, 100(2):309-314.

50. Bianchi SL, et al: Brain and behavior changes in 12-month-old Tg2576 and nontransgenic mice exposed to anesthetics. Neurobiol Aging 2008, 29(7):1002-1010

51. Rezzani R: Exploring cyclosporine A-side effects and the protective roleplayed by antioxidants: the morphological and immunohistochemical studies. Histol Histopathol 2006, 21(3):301-316.

52. Wu $X$, et al: The inhalation anesthetic isoflurane increases levels of proinflammatory TNF-alpha, IL-6, and IL-1beta. Neurobiol Aging 2012, 33(7):1364-1378.

53. Dingledine $\mathrm{R}$, et al: The glutamate receptor ion channels. Pharmacol Rev 1999, 51(1):7-61.

54. Zhang $Y$, et al: Anesthetics isoflurane and desflurane differently affect mitochondrial function, learning, and memory. Ann Neurol 2012, 71(5):687-698

55. Buljubasic N, et al: Effects of halothane and isoflurane on calcium and potassium channel currents in canine coronary arterial cells. Anesthesiology 1992, 76(6):990-998.

56. Friederich $\mathrm{P}$, Benzenberg D, Urban BW: Ketamine and propofol differentially inhibit human neuronal $\mathrm{K}(+)$ channels. Eur J Anaesthesiol 2001, 18(3):177-183.

57. Shao $\mathrm{H}$, et al: Dose-dependent protective effect of propofol against mitochondrial dysfunction in ischaemic/reperfused rat heart: role of cardiolipin. Br J Pharmacol 2008, 153(8):1641-1649.

doi:10.1186/2045-9912-2-20

Cite this article as: Zhang et al.: Propofol and magnesium attenuate isoflurane-induced caspase-3 activation via inhibiting mitochondrial permeability transition pore. Medical Gas Research 2012 2:20.

\section{Submit your next manuscript to BioMed Central and take full advantage of:}

- Convenient online submission

- Thorough peer review

- No space constraints or color figure charges

- Immediate publication on acceptance

- Inclusion in PubMed, CAS, Scopus and Google Scholar

- Research which is freely available for redistribution 